\title{
Experimental and Numerical Investigation on Humidity Distribution in an Environmental Chamber*
}

\author{
Liang PU**, Yanzhong $\mathrm{LI}^{* *}$, Yinhai ZHU** and Changyong GAO** \\ **Department of Refrigeration and Cryogenics Engineering, \\ School of Energy and Power Engineering, Xi'an Jiaotong University, Xi'an 710049, P.R.China \\ E-mail: puliang@mail.xjtu.edu.cn; yzli-epe@mail.xjtu.edu.cn
}

\begin{abstract}
Environmental chamber is widely used for testing the performance of the equipment with all kinds of natural ambient parameters. In this study, water droplet generated from ultrasonic humidifier is ascertained by laser diffraction measurement technology. The accurate droplet size and distribution is offered to CFD simulation as the initial condition. Humidity distribution with different initial conditions is studied by both experiment and CFD simulation. Comparisons show that the proposed CFD method can provide reliable results in simulation on the humidity distribution. The numerical and experimental results indicate that as the increase of inlet temperature, fluctuation of relative humidity $(\mathrm{RH})$ at each point decrease with the time. Under the inlet condition with low-humidity, the deviation of average RH is decrease with inlet temperature. On the other hand, under the high-humidity condition, the difference of average RH is getting larger with the increase of inlet temperature. Compared with the mean value, the fluctuation of the humidity is big but the RH at measuring points is close to the inlet RH value under the inlet condition with low humidity.
\end{abstract}

Key words: Environmental Chamber, Humidity Distribution, Numerical Simulation, Non-Uniformity

\section{Nomenclature}

$\phi \quad$ the general variable

$\Gamma_{\phi}$ the generalized diffusion coefficient

$S_{\phi} \quad$ the generalized source term

$N_{i} \quad$ the mass flow velocity of steam

$k_{i} \quad$ the mass transfer coefficient

$C_{i, s}$ the saturated steam concentration of water

$C_{i, \infty} \quad$ the steam concentration of the principle body of gas phase

$D_{i, m}$ the diffusion coefficient of steam

$S_{c}$ the Sechmit of mass transfer

$x \quad$ the RH non-uniformity 
$\varphi_{i}$ the RH value at measuring point
$\bar{\varphi} \quad$ the average $\mathrm{RH}$ value
$n \quad$ the number of measuring points

\section{Introduction}

Environmental chamber is widely used in the fields of national defense, electricity, electronics, and materials science, because it can be used as testing equipment for simulating natural ambient parameters such as temperature and humidity. An environmental chamber should maintain the uniformity and stability of all kinds of indoor parameter fields. Especially, a uniform and stabile humidity field is required to account for some problems such as long response time and inaccurate measurement. Humidity distribution is more difficult to reach stability than temperature field due to the influence of heat and moisture exchange. It is significant to research all the effects on the humidity distribution in the environmental chamber.

Computational Fluid Dynamics (CFD) is an effective tool for calculation of indoor flow field, temperature field and distribution of pollutant $[1,2]$. The literature [3] explored the influence of the indoor material volatilization on the indoor air quality of environmental chamber. The influence of border condition of ambient, conservation model, and numerical simulation efficiency to the solution for the humidity and heat transfer in the building were explored by Janssen et.al [4]. The mathematical model [5, 6] of the heat and moisture exchange for the indoor air in the building was explored and optimized by Lü. The numerical simulation of temperature field, flow field, and humidity diffusion etc. of the indoor air was made by Manzan and Saro [7].

In the recent years, the experimental and theoretical research on the environmental chamber is attracting more attention. The spray chamber of air-conditioning was developed based on the heat and moisture exchange, change of air situation due to temperature difference, non-uniformity of field and so on. Currently, research of indoor flow field and temperature field is focus on the study about concentration field. There were some studies about Indoor Air Quality (IAQ) and temperature field in the former studies on environmental chamber or indoor room. The influence of the indoor and outdoor temperature difference on the lost of moisture content and change of humidity in the air-conditioning system was studied by Aristov et.al [8]. Mutual influence among the parameters exists in the control of ambient humidity. The influence of ambient humidity and indoor humidity to the indoor temperature, i.e. the interacting relationship of all kinds of aspects such as humidity and temperature etc, was studied by Gaur and Bansal et.al [9]. The interacting among the conduction, convection, and radiation in the heat and moisture exchange to the heat-mass exchange was researched by Vasile et.al through the porous media [10]. However there are few researches on the humidity distribution. Studies on the law of droplet evaporation and distribution had been developed slowly.

In this study, two kinds of wrapping methods of humidity measurement are introduced and proved to be considerably effective, one is wet-bulb thermocouple wrapping with seven layers of pledget and another is thermocouple wrapping with cotton thread. Initial condition of inlet is studied and water droplet size and distribution generated from ultrasonic humidifier is ascertained by laser diffraction measurement technology. The humidity distribution in an environmental chamber is studied in different inlet conditions. In addition, the droplet distribution inside chamber is numerically simulated to predict the humidity distribution based on the ultrasonic humidifying method. By means of the volatilization model of water droplet, the CFD simulation studies are verified by compared to the 
corresponding experimental data. The research method and results of this study should provide reference for the researches on humidity distribution in human settlement and test environment.

\section{Numerical model approach}

\subsection{Environmental chamber description}

In this study, the environmental chamber and the effective working area are schematically shown in Fig. 1 . The cuboids, numbering from 1 to 13 , are samples to observe the humidity distribution in the working area. These points can be divided into three layers as upper, middle and bottom layer. The internal dimension of the chamber is $1.0 \mathrm{~m} \times 1.0 \mathrm{~m} \times 1.5 \mathrm{~m}$ and the dimension of the effective working area is $0.6 \mathrm{~m} \times 0.6 \mathrm{~m} \times 1.1 \mathrm{~m}$. Three inlets with the same dimension of $0.3 \mathrm{~m} \times 0.1 \mathrm{~m}$ locate in the upper, middle, lower part respectively. The outlet is at the bottom of the chamber with a dimension of $0.5 \mathrm{~m} \times 0.1 \mathrm{~m}$. In this study, the middle inlet is adopted for the experimental research and numerical simulation.

\subsection{Governing equations and algorithm}

The following assumptions are used in this CFD simulation:

(1) The inlet flow is steady state;

(2) The fluid flow meets the Boussinesq assumption;

(3) The fluid inside chamber is incompressible Newtonian fluid;

(4) The diameter of sprayed droplets is considered to be uniform and the ideal collision is treated when the droplets meet the solid wall;

(5) The computational fluid is the ideal gas mixture of dry air and water vapor. The liquid droplets do not contain dissolved air and the existence of air will not affect the balance between water vapor and the gathered steam. The average humidity and the partial pressure is calculated corresponding to the saturation temperature;

(6) Heat radiation is neglected.

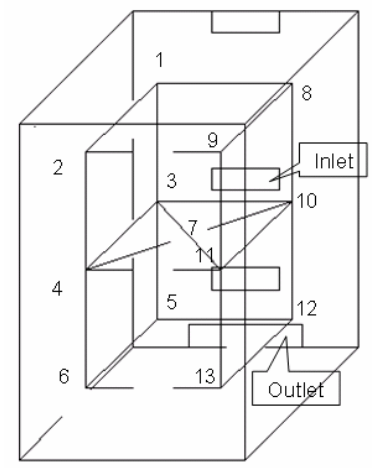

Fig.1 Model of the environmental chamber and the effective working area

In this study, CFD software FLUENT was employed to simulate the fluid flow field and humidity distribution inside environmental chamber. The Semi-implicit SIMPLER Algorithm method is applied to pressure conjugated problem in the turbulence flow calculation, and a second order upwind differential scheme was applied for the approximation of the convective terms.

There are several turbulence models available in the code. A standard $\mathrm{k}-\varepsilon$ model was used to predict turbulent flow inside chamber. Mass Conservation Equation [11]:

$$
\frac{\partial \rho}{\partial t}+\nabla \rho u=0
$$


General form of governing equation:

$$
\frac{\partial(\rho \phi)}{\partial t}+\operatorname{div}(\rho U \phi)=\operatorname{div}\left(\Gamma_{\phi} g r d \phi\right)+S_{\phi}
$$

Where $\phi$ is the general variable which represents $u, v, w, \mathrm{~T}, \mathrm{~K}, \varepsilon ; \Gamma_{\phi}$ is the generalized diffusion coefficient; $S_{\phi}$ is the generalized source term.

The molecular viscosity can be ignored in the zone which has a certain distance from the wall. A boundary condition is combined with wall function for treatment $[11,12]$, i.e. using speed boundary for inlet while pressure boundary for outlet. The wall surface may apply the second boundary condition defining its heat flux density.

In FLUENT calculation, the discrete phase model [13], the second discrete phase in the simulation of the flow field in the Lagrangian coordinates, is applied for all the bubbles, droplets and the particle load flow in a size of less than $10 \%$. The spherical particles (droplets or bubbles) constitute the second phase, and distributing in the continuous phase. As the particles pass through the control body, the momentum, heat and mass exchange of the particles for getting those values of the discrete phase (water droplet) transferred by the continuous phase (wet air) are calculated respectively. These exchange values as a "sink" will effect into the calculation of the subsequent fluid momentum and the conservation of energy and mass.

The droplet evaporation capacity is determined by the gradient diffusion, i.e. the diffusion velocity of droplets into the gas phase is correlated with the steam concentration gradient between the droplet surface and the principle body of airflow:

$$
N_{i}=k_{i}\left(C_{i, s}-C_{i, \infty}\right)
$$

Where $N_{i}$ is the mass flow velocity of steam $\left(\mathrm{kg} / \mathrm{m}^{2} \cdot \mathrm{s}\right)$; $k_{i}$ is the mass transfer $\operatorname{coefficient}(\mathrm{m} / \mathrm{s}) ; C_{i, s}$ is the saturated steam concentration of water $\left(\mathrm{kg} / \mathrm{m}^{3}\right) ; C_{i, \infty}$ is the steam concentration of the principle body of gas phase $\left(\mathrm{kg} / \mathrm{m}^{3}\right)$.

The mass transfer coefficient $\left({ }^{k_{i}}\right)$ can be calculated by the following:

$$
N u_{A B}=\frac{k_{i} d_{p}}{D_{i, m}}=2.0+0.6 \mathrm{Re}_{d}^{1 / 2} S_{c}
$$

Where $D_{i, m}$ is the diffusion coefficient of $\operatorname{steam}\left(\mathrm{m}^{2} \cdot \mathrm{s}^{-1}\right) ; S_{c}$ is the Sechmit number of mass transfer( $\left.\frac{\mu}{\rho D_{i, m}}\right)$.

\subsection{Boundary conditions}

Boundary conditions and convergent condition are as follows: inlet fluid velocity and temperature are given, and the pressure at outlet vent is specified. The third boundary condition is applied to all chamber walls. No slip occurs at the wall. Convergent criterion is specified to absolute residuals less than $1.0 \times 10^{-6}$. Tetrahedral grid is applied in the CFD calculation and the number of grids is about 220,000 . The total number of droplets is about 1 million per second. According the practical situation, Table 1 shows the material characteristic of enclosure structure. 
Table 1 The characteristic of enclosure structure

\begin{tabular}{cccc}
\hline $\begin{array}{c}\text { Enclosure } \\
\text { structure }\end{array}$ & $\begin{array}{c}\text { Coefficient of heat transfer } \\
\lambda / W \cdot \mathrm{m}^{-1} \cdot \mathrm{K}^{-1}\end{array}$ & Thickness $/ \mathrm{m}$ & Material \\
\hline Wall & 0.036 & 0.1 & $\begin{array}{c}\text { polythene } \\
\text { limestone and } \\
\text { Ground }\end{array}$ \\
top & 2.25 & 0.12 & $\begin{array}{c}\text { damproof material } \\
\text { polythene }\end{array}$ \\
\hline
\end{tabular}

Laser diffraction technology is applied to precision measurement in many research fields, such as nondestructive testing in industrial products, non-contact measurement of micro-cavity in medical science. The micro particle and quantity of water droplets are measured accurately by laser diffraction technology. In this study, ultrasonic humidifier is used for humidifying process. Laser diffraction measurement technology is adopted for accurately measuring drop size distribution of water droplets from ultrasonic humidifier. At the same time, the particle size distribution provides the initial condition for the latter CFD simulation in chamber.

Figure 2(a) shows drop size distribution of water droplets from ultrasonic humidifier. In order to simplify the problem and reduce computational complexity, the drop size distribution as shown in Fig. 2(b) is used for initial condition of CFD simulation.

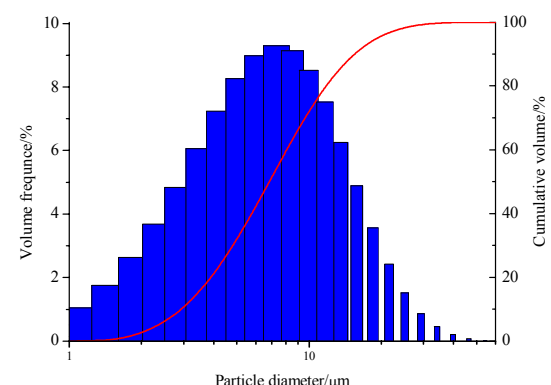

(a) Drop distribution of measurement

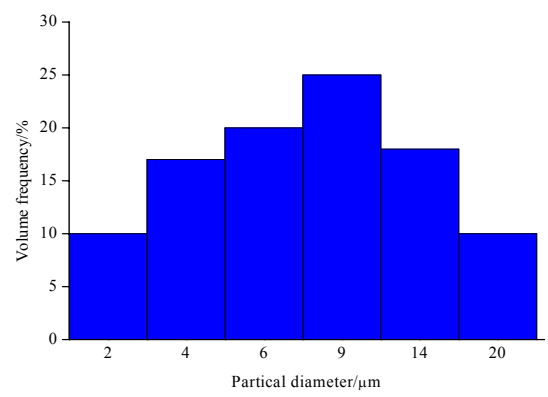

(b) Drop distribution of simplification

Fig.2 Drop size distribution

\section{Experimental setup}

\subsection{Experimental facility}

Figure 3 shows the experimental system, which consists of three parts: (1) Air handling system. (2) Environmental chamber. (3) Data acquisition system.

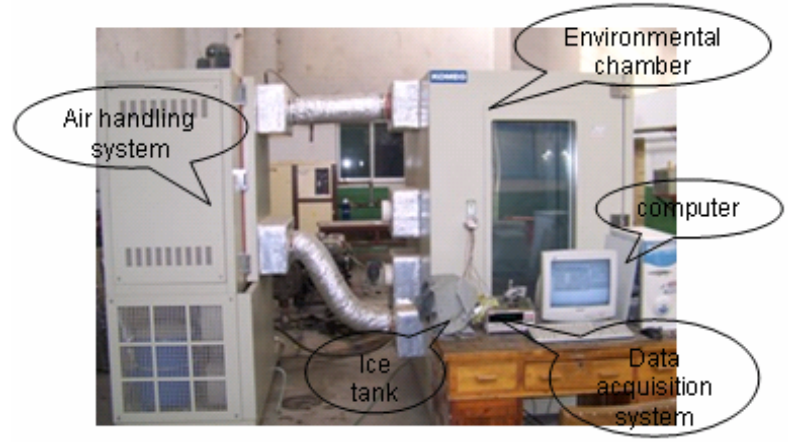

Fig.3 Arrangement diagram of experimental system

The processed air is supplied by air handling system and then comes into the environmental chamber. Thus the inlet air has certain temperature and humidity. There are 15 pairs of dry/wet bulb thermocouple at the inlet, outlet and 13 measurement points as located in Fig. 1. Dry bulb temperature and wet bulb temperature are acquired by measurement system firstly, and then relative humidity is gained by calculation. Velocity of 
every point is obtained by anemometer.

\subsection{Measuring method of humidity with dry/wet bulb thermocouple}

Figure 4 is a schematic diagram showing of experiment. A fan and two thermocouples are located in front and rear of straight pipe segment respectively. Pipe diameter is $160 \mathrm{~mm}$ and pipe length is $650 \mathrm{~mm}$. The thermocouples are wrapped with seven layers pledget and cotton thread of $3 \mathrm{~mm}$ diameter respectively. The straight pipe segment plays a role to drift the air current so that the air velocity via thermocouples and anemoscope will be stable and even. The whole testing segment locates in the experimental chamber with RH $60 \%$.

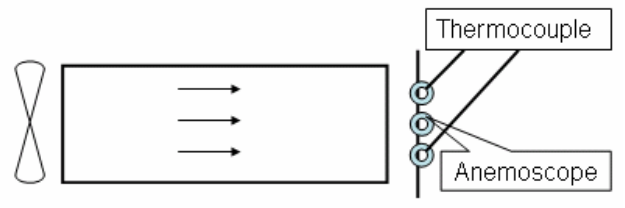

Fig.4 Schematic diagram of experiment

The experimental data are shown in Fig.5. The result shows that the $\mathrm{RH}$ of seven layers pledget wrapping method is more than that of cotton-thread method under the air velocity is less than $1 \mathrm{~m} / \mathrm{s}$. The result also means that the water of seven layers pledget wrapping method is vaporized relatively slowly and its wet bulb temperature is slightly higher than that of cotton thread method. The deviation in the two methods is small when the air velocity is from 1 to $3.5 \mathrm{~m} / \mathrm{s}$. It means that the measuring error of both methods is equivalent within the air velocity range and it is controllable and allowable. The measured $\mathrm{RH}$ value deviates as the air velocity is more than $3.5 \mathrm{~m} / \mathrm{s}$. When air velocity increases, the rate of water evaporation increases and the wet bulb temperature and $\mathrm{RH}$ value decrease. It is found that the measured two RH values deviate as the air velocity is more than $3.5 \mathrm{~m} / \mathrm{s}$.

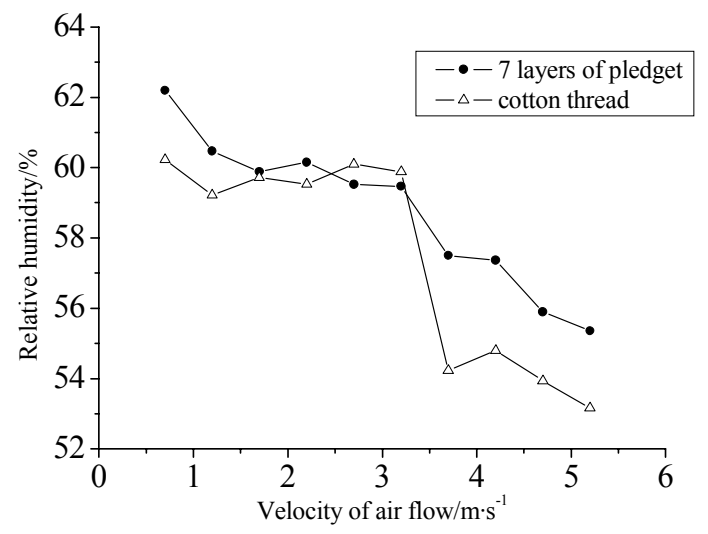

Fig.5 RH of two kinds of wrapping mode with different air velocity

Through calculation, the relative measuring error of $\mathrm{RH}$ is limited not to exceed $1.5 \%$ as air velocity is less than $3.5 \mathrm{~m} / \mathrm{s}$. Moreover, the velocity of all measurement points in chamber is under $3.5 \mathrm{~m} / \mathrm{s}$. So thermocouple with cotton thread wrapping way is adopted in this study.

\section{Experimental results and discussion}

The variance and standard deviation may describe the deviation degree between the measuring value and mean value. In this study, the standard deviation of RH is used to analyze the uniformity of RH distribution. The non-uniformity of RH is defined as follows:

$$
x=\sqrt{\frac{\sum_{i=1}^{n}\left(\varphi_{i}-\bar{\varphi}\right)^{2}}{n}}
$$


Where $\varphi_{i}$ is the RH value at measuring point; $\bar{\varphi}$ is the average RH; $n$ is the number of measuring points.

\subsection{Effects of Inlet Air Temperature on Time Characteristic of RH}

A series of experiments are carried out in the environmental chamber under different inlet $\mathrm{RH}$ from $20 \%$ to $80 \%$ and different inlet temperature $20{ }^{\circ} \mathrm{C}, 40{ }^{\circ} \mathrm{C}$ and $60{ }^{\circ} \mathrm{C}$ respectively. In consideration of the symmetrical arrangement between point 1-6 and point 8-13 as shown in Fig. 1(b), only the results of point 1-7 are demonstrated in the following figures.

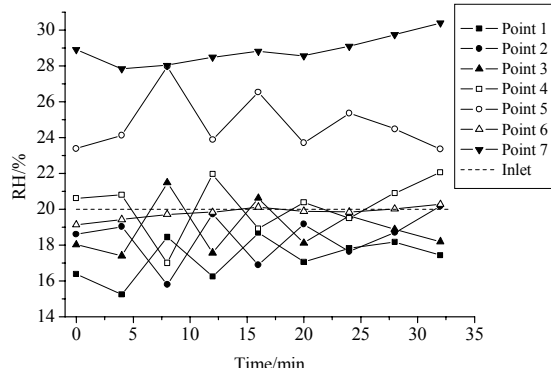

(a) Inlet air at $\mathrm{RH} 20 \%$

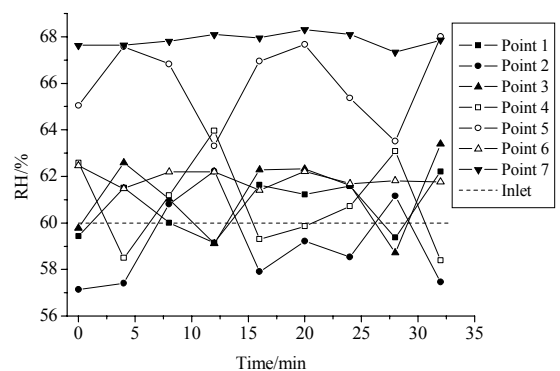

(c) Inlet air at RH60\%

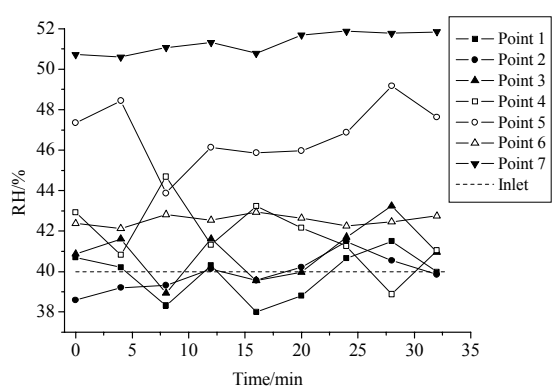

(b) Inlet air at RH40\%

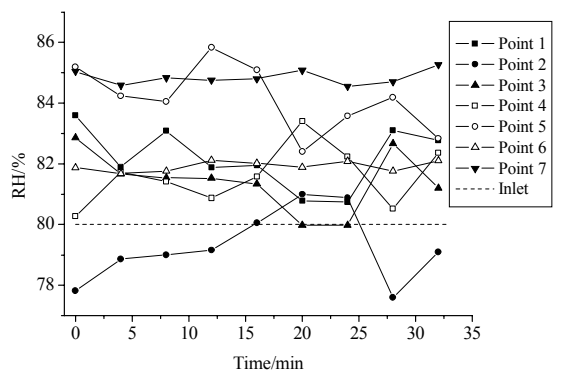

(d) Inlet air at $\mathrm{RH} 80 \%$

Fig. $6 \mathrm{RH}$ of the measuring point changing with the time at $20^{\circ} \mathrm{C}$

Firstly, as an example, the situation with low inlet temperature is studied that the inlet temperature is $20{ }^{\circ} \mathrm{C}$ and the inlet $\mathrm{RH}$ is $20 \%, 40 \%, 60 \%$ and $80 \%$ respectively. Fig. 6 shows that the RH at the measuring point is changing with the time. The results show that under the condition with inlet RH $20 \% 40 \%, 60 \%$ and $80 \%$, the absolute deviation of all points is less than $10 \%, 12 \%, 8 \%$ and $6 \%$ respectively.

Similarly, when the inlet temperature is $40{ }^{\circ} \mathrm{C}$ and $60{ }^{\circ} \mathrm{C}$, the $\mathrm{RH}$ absolute deviation of all points can be obtained respectively. Table 2 shows the absolute deviation of different inlet conditions.

Tab. 2 Absolute deviation of $\mathrm{RH}$ under different inlet condition

\begin{tabular}{ccccc}
\hline \multirow{2}{*}{ Inlet temperature $/{ }^{\circ} \mathrm{C}$} & \multicolumn{4}{c}{ Inlet $\mathrm{RH} / \%$} \\
\cline { 2 - 5 } & 20 & 40 & 60 & 80 \\
\hline 20 & $<10$ & $<12$ & $<8$ & $<6$ \\
40 & $<10$ & $<6$ & $<8$ & $<8$ \\
60 & $<4$ & $<6$ & $<6$ & $<8$ \\
\hline
\end{tabular}

Under the above inlet temperature conditions, the deviations of $\mathrm{RH}$ at point 5 and point 7 are higher than the others, and that of point 7 is more remarkable. Temperature of point 5 and 7 are lower than inlet temperature because these two points are near the outlet. In addition, the moisture content has no effective diffusion, so the local $\mathrm{RH}$ value is high. The 
fluctuation value of $\mathrm{RH}$ decreases with inlet $\mathrm{RH}$ increasing under low temperature inlet condition and the change tendency is opposite under high temperature inlet condition.

Under the same RH value, humidity content is relative low at low temperature and the humidity distribution can reach uniform condition easily at higher inlet $\mathrm{RH}$ to result that the fluctuation value of $\mathrm{RH}$ decreases from $10 \%$ to $6 \%$ with inlet $\mathrm{RH}$ increasing at $20{ }^{\circ} \mathrm{C}$ inlet. In contrast, humidity content is relative high at high temperature. Although high temperature leads to intense evaporation, however, excessively high RH (high humidity content) can destroy the uniform distribution. Hence, the fluctuation value of RH increases from $4 \%$ to $8 \%$ with inlet $\mathrm{RH}$ increasing at $60{ }^{\circ} \mathrm{C}$ inlet.

\subsection{Research of Time Characteristic for the Average RH Changing with Different Inlet Temperature}

The time characteristic curve of the average $\mathrm{RH}$ at the measuring point in the working area changing with the inlet air temperature is shown as Fig.7 (The inlet RH is fixed):

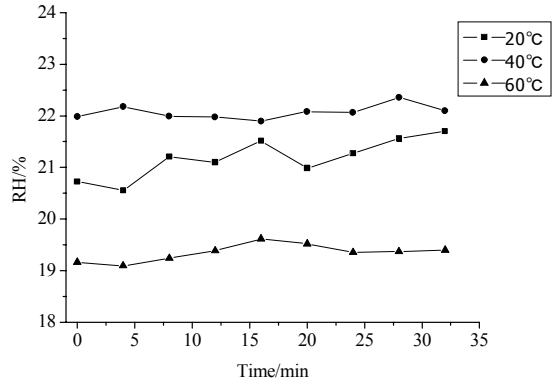

(a) Inlet air at RH $20 \%$

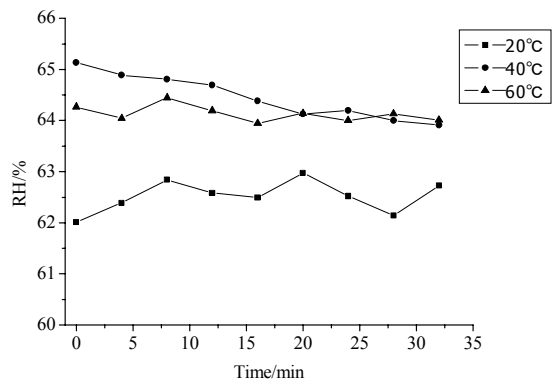

(c) Inlet air at RH $60 \%$

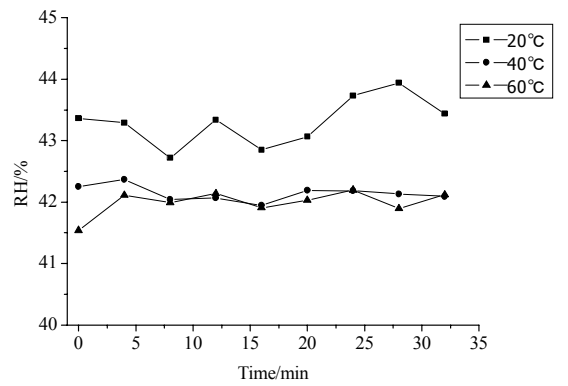

(b) Inlet air at $\mathrm{RH} 40 \%$

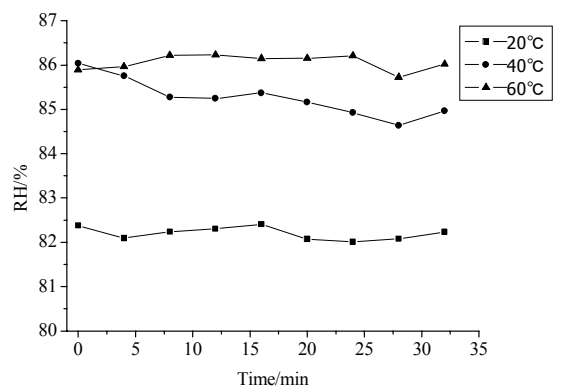

(d) Inlet air at $\mathrm{RH} 80 \%$

Fig. 7 Average $\mathrm{RH} \%$ of the measuring points versus the time at certain inlet $\mathrm{RH}$

The result shows that, under the condition with inlet RH $20 \%$ of Fig. 7(a), no matter how the inlet air temperature is, the absolute deviation of average $\mathrm{RH}$ at the measuring points in the working area are within $2 \%$. As the inlet air RH is increasing, the absolute deviation is increasing. As shown in Fig. 7(b), 7(c) and 7(d), under the condition with inlet RH $40 \%, 60 \%$ and $80 \%$, the absolute deviation is about within $4 \%, 5 \%$, and $6 \%$ respectively. On the other hand, the relative deviations of the average $\mathrm{RH}$ under the above four cases are all within $10 \%$.

Under the inlet condition with low RH, the deviation between the average $\mathrm{RH}$ and the inlet RH is small with high temperature inlet, and the deviation is large as the inlet temperature is low. On the other hand, the difference between the average RH and the inlet $\mathrm{RH}$ is becoming larger with inlet temperature increasing with high $\mathrm{RH}$ inlet. At high temperature and low RH inlet condition, humidity distribution is easy to reach uniform as the droplets are apt to evaporate. On the other hand, humidity distribution is also easy to reach uniform at low temperature and high $\mathrm{RH}$ inlet condition. 


\section{CFD numerical studies}

\subsection{Comparison of experimental and simulation results}

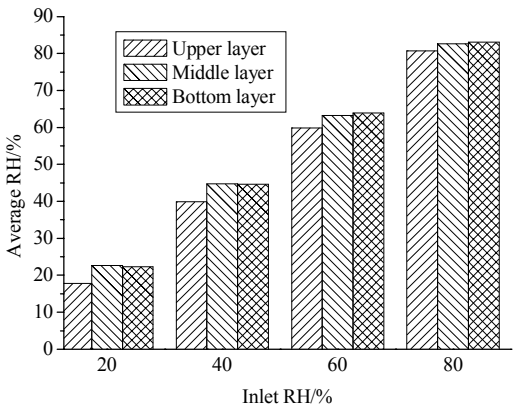

(a) Experimental results

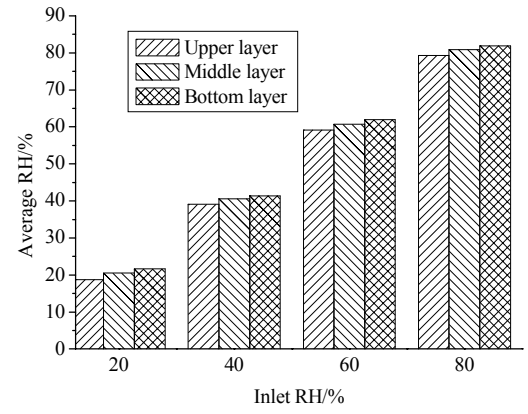

(b) CFD results

Fig. 8 Average humidity changing with inlet humidity at $20^{\circ} \mathrm{C}$

There are three layers of measuring points inside chamber as above mentioned. Average RH of each layer from the experimental and simulation are compared in Fig .8 at the inlet temperature of $20^{\circ} \mathrm{C}$. The results show that, under the condition of the middle inlet, the average humidity of the upper layer is low, and it is less than the inlet RH. The average $\mathrm{RH}$ of middle layer and bottom layer are close to the inlet RH. It means that the inlet flow will slightly influence the upper layer under the condition with the middle inlet. Therefore, the humidity of the upper layer can hardly meet the humidity requirement.

Non-uniformity of RH is calculated by Formula (5) as above mentioned. Fig. 9 shows the time characteristic of the non-uniformity of RH with different inlet humidity under fixed inlet temperature.

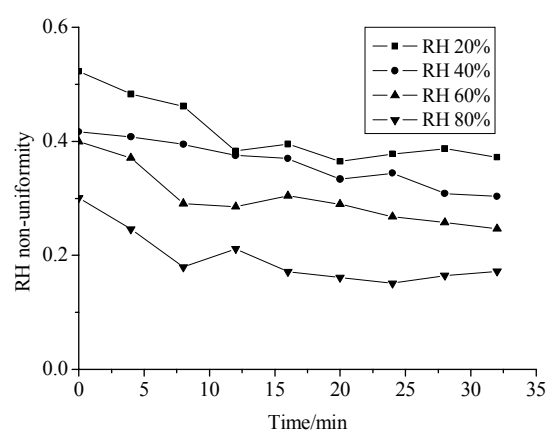

(a) Experimental results

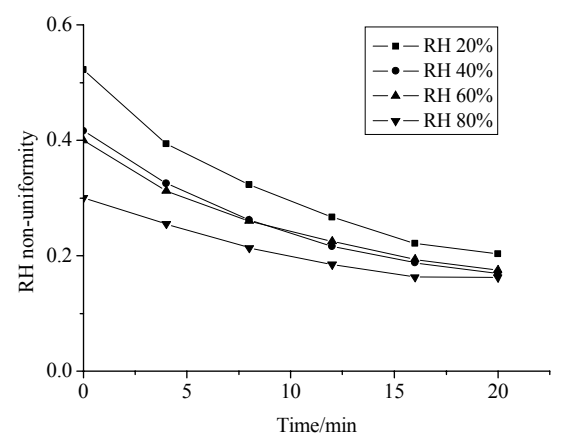

(b) CFD results

Fig. 9 Time characteristic of the $\mathrm{RH}$ non uniformity at $20^{\circ} \mathrm{C}$

The experimental results show that under the condition with different inlet temperature and $\mathrm{RH} 20 \%$, the non-uniformity of $\mathrm{RH}$ in the working area is big. The non-uniformity of $\mathrm{RH}$ decreases with the increase of inlet $\mathrm{RH}$, but the RH difference between each point and inlet is larger with the increase of inlet RH as above mentioned, which should be paid attention to.

According to the time characteristic of humidity, although the non-uniformity is big under inlet condition of low $\mathrm{RH}$, the $\mathrm{RH}$ at measuring point is close to the inlet humidity. However, under the inlet condition of high $\mathrm{RH}$, although the non uniformity is small, the $\mathrm{RH}$ deviation between the measuring point and that of inlet air is large.

The results show that RH non-uniformity gradually tends to zero with time progress, and the humidity distribution inside the chamber can reach stable value with time progress. The result has a good agreement with the actual situation. On the other hand, the consumed time in CFD method to obtain a stable RH distribution is shorter than that in experiment. 
From Fig. 9(a) and (b), it is found that the time characteristic of RH non-uniformity is not in good agreement, especially after 15 minutes. One possible explanation is that the factors, such as the fluctuating environment conditions and the fluctuating inlet conditions et.al, are not considered in calculation.

\subsection{CFD results and discussions}

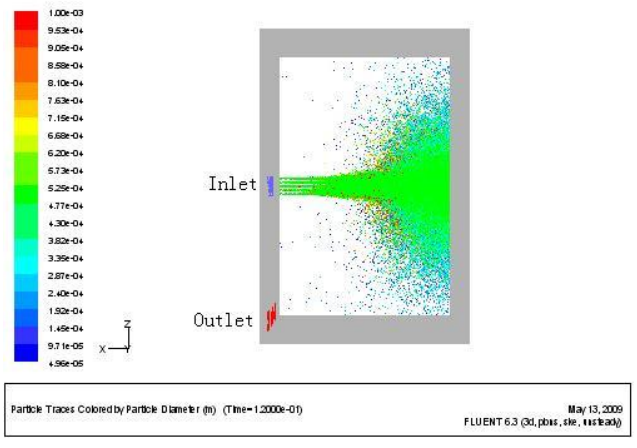

(a) Side view $(y=0.5 \mathrm{~m})$
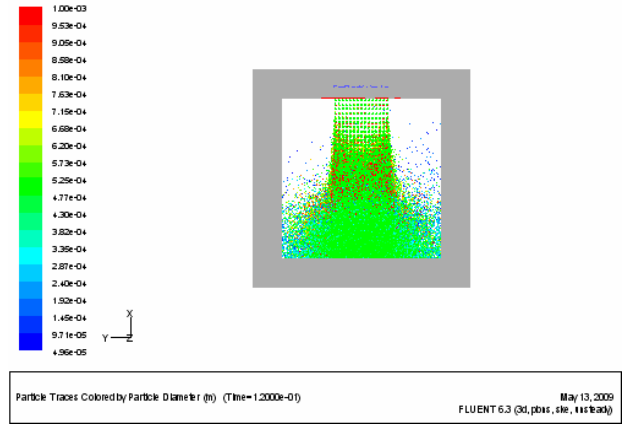

(b) Planform $(\mathrm{z}=0.75 \mathrm{~m})$

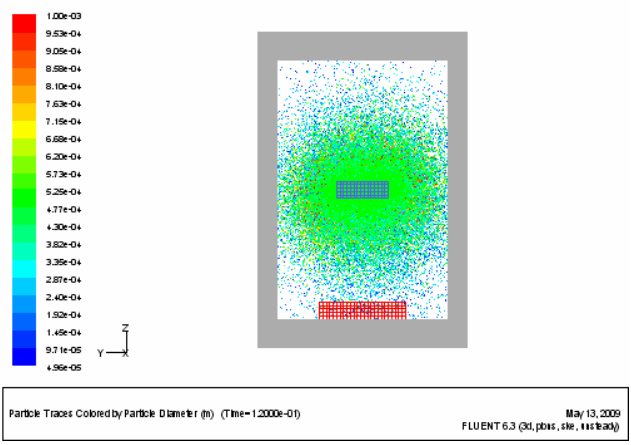

(c) Front view $(\mathrm{x}=0.5 \mathrm{~m})$

Fig. 10 CFD simulation results of droplet distribution

As an example, Fig. 10 shows the droplet distribution from CFD simulation. The inlet condition is $8 \mathrm{~m} / \mathrm{s}, 40{ }^{\circ} \mathrm{C}$ and $\mathrm{RH} 20 \%$. Droplet size and distribution is adopted as Fig. 2(b).

Figure 10 shows humidity distribution inside chamber from macroscopic angle. Asymmetric distribution of water droplets exists in X-Z plane as shown in Fig. 10(a), due to mutual influence of forced convection and droplet sedimentation. In X-Y plane and Y-Z plane as shown in Fig. 10(b) and 10(c).

Seen from Fig. 10(a) and Fig. 11, droplet chaos are easy to be generated in vortex area and recirculation zone. In addition, the humidity content near the front of chamber is denser than that near the inlet.

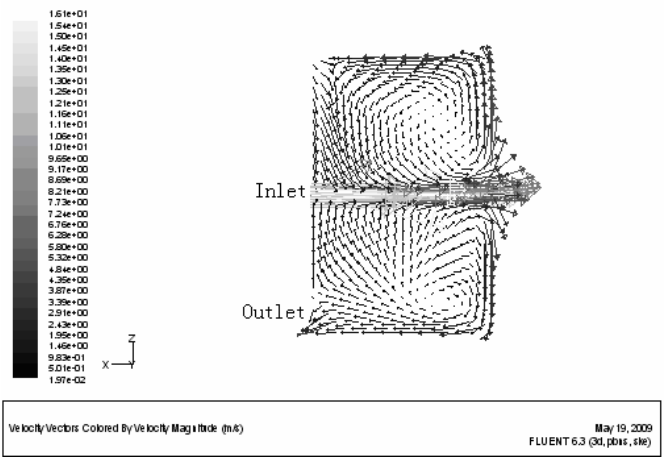

Fig. 11 Side view of the velocity vector 


\section{Conclusions}

In this study, laser diffraction technology is applied to measure the size and distribution of water droplets at the environment chamber inlet. Two humidity measurement methods were experimentally compared and the results show that thermocouple with cotton thread wrapping way can meet the demand of the precision for humidity measurement. A series of experiments in the environmental chamber were carried out under different inlet conditions. The influence of the inlet temperature and RH on the humidity distribution and its time characteristic was carefully investigated.

The main conclusions from the experiment and CFD studies are given as follows:

(1) The RH value at each point is difficult to reach stable due to the forced convection. $\mathrm{RH}$ fluctuation with the time at each point decreases with inlet temperature, i.e. the $\mathrm{RH}$ stability is good with high inlet temperature.

(2) Under the inlet condition of low RH, the deviation of average RH is small at high temperature of inlet and the deviation is large at low temperature of inlet. On the other hand, the difference between the average $\mathrm{RH}$ and the inlet $\mathrm{RH}$ is becoming larger with inlet temperature increasing under the inlet condition of high $\mathrm{RH}$.

(3) The non-uniformity of RH decreases with the increase of inlet RH. The humidity fluctuation is big with low humidity of inlet, but the RH of each point is close to the inlet humidity value. However, the RH difference between the measuring point and the inlet is large with high inlet humidity.

(4) Comparisons show that CFD results are in good agreement with experimental data. CFD method is capable of accurate study on the humidity distribution in environmental chamber under different conditions.

The laser diffraction measurement of water droplets can be applied to other humidifying processes. With droplet size distribution condition and volatilization model, the proposed CFD simulation method can be applied to similar research of environmental chamber.

\section{Acknowledgement}

The author would like to thank Xi'an Jiaotong University for the President Foundation of Xi'an Jiaotong University (XJJ2008045).

\section{References}

[1] K. Mohamed, M. Paraschivoiu. Real gas numerical simulation of hydrogen flow[C]//2nd International Energy Conversion Engineering Conference. Providence: American Institute of Aeronautics and Astronautics Inc., 2004: 727-740.

[2] C. Stan, H. Eichert, L. Martorano et.al. Fluid dynamic modeling of gasoline direct injection for compact combustion chambers[C]//SAE International Congress. Baltimore, MD: SAE Publication, 1998: 1-10.

[3] J. S. Zhang, J. M. Kanabus-Kaminska, C. Y. Shaw. Full-scale test chamber for material emission studies and indoor air quality modeling [J]. ASTM Special Technical Publication, 1996, 1287(1): 58-66.

[4] Hans Janssen, Bert Blocken and Jan Carmeliet. Conservative modelling of the moisture and heat transfer in building components under atmospheric excitation: International Journal of Heat and Mass Transfer,2007,50(5-6): 1128-1140.

[5] Xiaoshu Lü. Modelling of heat and moisture transfer in buildings: I. Model program: Energy and Buildings.2002,34(10): 1033-1043.

[6] Xiaoshu Lü. Modelling of heat and moisture transfer in buildings: II. Applications to indoor thermal and moisture control: Energy and Buildings.2002,34(10): 1045-1054.

[7] Marco Manzan and Onorio Saro. Numerical analysis of heat and mass transfer in a 
passive building component cooled by water evaporation: Energy and Buildings. 2002,34(4): 369-375.

[8] Yu.I. Aristov, I.V. Mezentsev and V.A. Mukhin. A new approach to regenerating heat and moisture in ventilation systems: Energy and Buildings, 2007,37(1): 1-5.

[9] R. C. Gaur and N. K. Bansal. Effect of moisture transfer across building components on room temperature: Building and Environment.2002,37(1): 11-17.

[10] C. Vasile, S. Lorente and B. Perrin. Study of convective phenomena inside cavities coupled with heat and mass transfers through porous media-application to vertical hollow bricks--a first approach: Energy and Buildings. 1998,28(3): 229-235.

[11] Wenquan Tao, Numerical Heat Transfer [M]. Xi'an: Xi'an Jiaotong University Press, 2002 (in Chinese).

[12] Zhongqi Lu. Tow-phase Flow \& Boiling Heat Transfer [M]. Beijing: Tsinghua University Press, 2002 (in Chinese).

[13] Zhanzhong Han, Jing Wang, Xiaoping Lan. FLUENT--Emulational Example \& Application on the Fluid Engineering [M]. Beijing: BeiJing Institute of Technology Press, 2004 (in Chinese). 